\title{
CYP2D6 polymorphisms influence the efficacy of adjuvant tamoxifen in Thai breast cancer patients
}

This article was published in the following Dove Press journal:

Pharmacogenomics and Personalized Medicine

16 October 2012

Number of times this article has been viewed

\author{
Ekaphop Sirachainan' \\ Sureerat Jaruhathai ${ }^{\prime}$ \\ Narumol Trachu ${ }^{2}$ \\ Ravat Panvichian' \\ Thitiya Sirisinha' \\ Touch Ativitavas' \\ Vorachai Ratanatharathorn' \\ Montri Chamnanphon ${ }^{3}$ \\ Chonlaphat Sukasem ${ }^{3}$ \\ 'Division of Medical Oncology, \\ Department of Medicine, ${ }^{2}$ Research \\ Center, Division of Pharmacogenomics \\ and Personalized Medicine, Department \\ of Pathology, Faculty of Medicine, \\ Ramathibodi Hospital, Mahidol \\ University, Bangkok, Thailand, ${ }^{3}$ Division \\ of Pharmacogenomics and Personalized \\ Medicine, Department of Pathology, \\ Faculty of Medicine Ramathibodi Hospital, \\ Mahidol University, Bangkok, Thailand
}

Correspondence: Ekaphop Sirachainan Division of Medical Oncology, Department of Medicine, Faculty of Medicine Ramathibodi Hospital, Rama 6 Road, Phayathai, BKK, 10400, Thailand

Tel +66220 | $|67|$

Fax +66 220I 167।

Email ekaphop.sir@mahidol.ac.th

Chonlaphat Sukasem;

Division of Pharmacogenetics

and Personalized Medicine,

Department of Pathology, Faculty of Medicine Ramathibodi Hospital, Rama 6 Road, Phayathai, BKK,

10400, Thailand

$\mathrm{Tel}+6622004331$

Fax +66 22004332

Email chonlaphat.suk@mahidol.ac.th
Aim: We evaluated single nucleotide polymorphisms (SNPs) of CYP2D6 to identify those that influence the efficiency of tamoxifen in adjuvant treatment of breast cancer through a matched case-control study.

Methods: Peripheral blood DNA was collected from 20 patients with disease recurrence during adjuvant tamoxifen treatment and from 19 patients who had completed 5 years of tamoxifen therapy without recurrence of breast cancer. CYP2D6*4 (1846G > A; rs3892097), CYP2D6*10 (100C $>\mathrm{T}, \mathrm{rs} 1065852$ ), and $C Y P 2 D 6 * 5$ (deletion) were genotyped. The correlation between disease-free survival (DFS) and genotype and clinical outcome were assessed using KaplanMeier analysis and a log-rank test.

Results: We found the allelic frequency of $C Y P 2 D 6^{*} 10$ during this study. Patients with the CYP2D6*10 homozygous variant $\mathrm{T} / \mathrm{T}$ genotype had a significantly shorter median of DFS than those with $\mathrm{C} / \mathrm{T}(P=0.036)$, but DFS was not significantly different from that of patients with the $\mathrm{C} / \mathrm{C}$ genotype $(P=0.316)$. One patient who was a carrier both of CYP2D6 G/A $(1846 \mathrm{G}>\mathrm{A})$ and $\mathrm{T} / \mathrm{T}(100 \mathrm{C}>\mathrm{T})$ had DFS of 22.7 months.

Conclusions: This study demonstrated that $C Y P 2 D 6^{*} 10 / * 10$ was significantly associated with shorter DFS in Thai breast cancer patients receiving tamoxifen. This was a pilot study investigating the correlation of CYP2D6 polymorphisms and their influence on clinical outcomes in Thai estrogen receptor-positive breast cancer patients.

Keywords: breast cancer, CYP2D6 polymorphism, pharmacogenetics, single-nucleotide polymorphism (SNP), tamoxifen

\section{Introduction}

Tamoxifen is a prodrug that requires conversion to active metabolites by the cytochrome P450 enzyme CYP2D6, which is one of the key enzymes for the formation of $\mathrm{N}$-desmethyltamoxifen and 4-hydroxytamoxifen. ${ }^{1,2} \mathrm{~N}$-desmethyltamoxifen is further metabolized to endoxifen, which has more potent antiestrogenic effects than tamoxifen. ${ }^{3}$ Breast cancer is currently the most common cancer in Thai women. Tamoxifen is the most commonly prescribed drug for the treatment and prevention of recurrence for patients with estrogen receptor (ER)-positive disease. ${ }^{4,5}$ However, the clinical response to tamoxifen varies widely among patients; not all ER-positive breast cancer patients benefit from tamoxifen therapy. ${ }^{6}$ Recent studies suggest that inherited variations in enzymatic activity responsible for the metabolism of tamoxifen affects the risk of breast cancer recurrence in patients receiving adjuvant tamoxifen. ${ }^{7-9}$ Patients receiving tamoxifen who either carry genetic variants associated with low or absent CYP2D6 activity have a significantly lower plasma level of endoxifen. ${ }^{3,10-12}$ 
The frequency of the CYP2D6 poor metabolizer phenotype varies across different populations. ${ }^{13}$ Caucasians have the highest frequency of the poor metabolizer phenotype at a frequency of $7 \%-10 \%$, with CYP2D $6 * 4(1846 \mathrm{G}>\mathrm{A})$ being a major variant..$^{14-18}$ Only $1 \%-3 \%$ of poor metabolizers from the Asian population have CYP2D6*5 (gene deletion) as a major variant. However, the allele $C Y P 2 D 6^{*} 10$ $(100 \mathrm{C}>\mathrm{T})$ is a major variant that has been observed with a frequency of $40 \%-50 \%$ in Asian populations. ${ }^{19-22}$

Previous studies have shown that an association exists between $C Y P 2 D 6^{*} 4$ genotypes and clinical outcomes in Caucasians. ${ }^{23}$ Chinese women with the CYP2D6*10 $(100 \mathrm{C}>\mathrm{T}) \mathrm{T} / \mathrm{T}$ genotype have a significantly worse disease-free survival (DFS) than those with the $\mathrm{C} / \mathrm{C}$ or $\mathrm{C} / \mathrm{T}$ genotype. ${ }^{20}$ However, the association between the CYP2D6 genotype and tamoxifen efficacy in Thai patients has never been reported. The present study examined which CYP2D6 polymorphisms influence tamoxifen efficacy in Thai patients receiving adjuvant treatment for breast cancer. We conducted a matched case-control study in breast cancer patients who received adjuvant tamoxifen to determine the association of CYP2D6 polymorphisms and DFS.

\section{Methods}

\section{Patients and study design}

We enrolled 39 breast cancer patients in Ramathibodi Hospital who met our inclusion criteria, including (1) histological diagnosis of estrogen- and/or progesterone receptor-positive breast cancer, (2) received tamoxifen as an adjuvant treatment for breast cancer, and (3) age at diagnosis $>18$ years old. Exclusion criterion for patients in our study included if patients had started tamoxifen therapy along with other cytotoxic chemotherapy or any other endocrine therapy besides tamoxifen. Women taking other medicines known to inhibit CYP2D6 activity were also excluded. All subjects provided written consent before study entry. This study was approved by Ramathibodi's ethics committee.

Patients were classified into case and control groups. Case patients consisted of patients who had recurrence of breast cancer while receiving tamoxifen; patients who had already completed 5 years of adjuvant tamoxifen treatment were included as controls. Patient data was collected from medical records. We matched one control subject per case patient by age at diagnosis of breast cancer, menstruation status, type of surgery, date of surgery, ER/progesterone receptor ( $\mathrm{PgR}$ ) status, Her-2 status, histologic grading tumor, surgery margin status, lymphovascular involvement status, T stage of tumor, nodal involvement, number of nodes dissection, start and stop date of chemotherapy either neoadjuvant or adjuvant setting, start and stop date of adjuvant radiotherapy, start and stop date of tamoxifen. Date and site of the first disease relapse were collected.

\section{Genomic analysis}

Genomic DNA was extracted and amplified by PCR. The CYP2D6*4 (1846G > A; rs3892097) allele was detected by using restriction fragment length polymorphism (RFLP) techniques with the enzyme BstNI. The CYP2D6*10 $(100 \mathrm{C}>\mathrm{T}$; rs 1065852) allele was detected using DNA sequencing techniques with Big Dye Terminator Cycle Sequencing Kit and the ABI 3100 Genetic Analyzer (all from Applied Biosciences, Foster City, CA). We analyzed sequences using Chroma software to compare the DNA sequence alignment with a wild type reference. Resequencing was conducted using a reverse primer. TaqMan ${ }^{\circledR}$ Copy Number Assays (Applied Biosystems) were used to genotype the CYP2D6*5 (Hs.04083572_cn). Applied Biosystems CopyCaller ${ }^{\mathrm{TM}}$ Software was used for copy number analysis.

\section{End points and statistical analyses of associations}

An association between CYP2D6 polymorphisms and any influence of tamoxifen efficacy in adjuvant treatment of breast cancer and DFS were analyzed in this study. DFS was defined as the time from surgery to the occurrence of breast event (ie, local, regional or distant occurrence or contralateral breast cancer) or death from any cause. Patients who were alive without a breast recurrence were censored at the date of their last disease evaluation. The overall distribution of DFS was estimated using Kaplan-Meier methods. A log-rank test was used to assess the association between the factor and the event of interest.

\section{Results}

\section{Patient characteristics}

Patient characteristics are shown in Table 1. Among the 39 subjects, median age was 46.12 years (range 30-66 years). Overall, patient baseline characteristics were similar, including age, menopausal status, tumor size, tumor grading, and ER status, although a higher percentage had lymphovascular involvement, progesterone receptor and Her-2 status positive in group 1. The numbers of pre- and postmenopausal patients were 31 and 8, respectively. Median DFS was 31.05 months and 96.4 months in case and control groups, respectively $(P<0.005)$. Median follow-up time was 52.3 and 97.4 months in case and control groups, respectively $(P=0.02)$. 
Table I Patient characteristics

\begin{tabular}{|c|c|c|c|}
\hline Characteristic & $\begin{array}{l}\text { Patients arm I } \\
\text { (case group) } \\
\mathbf{n}=\mathbf{2 0}\end{array}$ & $\begin{array}{l}\text { Patient arm } 2 \\
\text { (control group) } \\
\mathrm{n}=19\end{array}$ & $P$-value \\
\hline \multicolumn{4}{|l|}{ Age, years } \\
\hline$<35$ & 14 & 2 & \\
\hline $35-55$ & 3 & 14 & \\
\hline$>55$ & 3 & 3 & \\
\hline Median age (years) & 45.8 & 46.47 & 0.832 \\
\hline $\begin{array}{l}\text { Median DFS } \\
\text { (months) }\end{array}$ & 31.05 & 96.4 & $<0.005$ \\
\hline $\begin{array}{l}\text { Median time F/U } \\
\text { (months) }\end{array}$ & 52.3 & 97.4 & 0.02 \\
\hline \multicolumn{4}{|l|}{ Menopausal status } \\
\hline Premenopausal & $16(80 \%)$ & I 5 (78.9\%) & 0.935 \\
\hline Postmenopausal & $4(20 \%)$ & $4(21.1 \%)$ & \\
\hline \multicolumn{4}{|l|}{ Tumor size $(\mathrm{cm})$} \\
\hline$<2$ & $4(20 \%)$ & $3(15.8 \%)$ & 0.943 \\
\hline $2-5$ & 15 (75\%) & 15 (78.9\%) & \\
\hline$>5$ & I (5\%) & $\mathrm{I}(5.3 \%)$ & \\
\hline \multicolumn{4}{|l|}{ Grading tumor } \\
\hline I & $3(15 \%)$ & $3(15.8 \%)$ & 0.831 \\
\hline 2 & II (55\%) & $9(47.4 \%)$ & \\
\hline 3 & $3(15 \%)$ & $2(10.5 \%)$ & \\
\hline Unknown & $3(15 \%)$ & $5(26.3 \%)$ & \\
\hline \multicolumn{4}{|c|}{ No of positive nodes } \\
\hline 0 & $10(50 \%)$ & $9(47.4 \%)$ & 0.987 \\
\hline $1-3$ & $5(25 \%)$ & $5(26.3 \%)$ & \\
\hline$\geq 4$ & $5(25 \%)$ & $5(26.3 \%)$ & \\
\hline \multicolumn{4}{|c|}{ Lymphovascular invasion } \\
\hline Positive & $18(90 \%)$ & $10(52.6 \%)$ & 0.01 \\
\hline Negative & $2(10 \%)$ & 9 (47.4\%) & \\
\hline \multicolumn{4}{|l|}{ ER status } \\
\hline Positive & $20(100 \%)$ & $19(100 \%)$ & \\
\hline Negative & 0 & 0 & \\
\hline \multicolumn{4}{|l|}{ PgR status } \\
\hline Positive & 13 (65\%) & $4(2 \mid \%)$ & $<0.005$ \\
\hline Negative & $3(15 \%)$ & I (5.3) & \\
\hline Unknown & $4(20 \%)$ & 14 (73.7\%) & \\
\hline \multicolumn{4}{|l|}{ Her-2 status } \\
\hline Positive 3+ & $2(10 \%)$ & $0(0 \%)$ & $<0.005$ \\
\hline Negative & 10 (50\%) & $2(10.5 \%)$ & \\
\hline Unknown & 8 (40\%) & I7 (89.5\%) & \\
\hline
\end{tabular}

Abbreviations: DFS, disease-free survival; ER, estrogen receptor; F/U, follow-up; PgR, progesterone receptor.

\section{Genotype and allele frequency}

We determined CYP $2 D 6^{*} 10$ genotypes of the 39 patients. A total of 19 patients $(19 / 39 ; 48.7 \%)$ were homozygous (T/T); $11(11 / 20 ; 55 \%)$ and $8(8 / 19 ; 42.1 \%)$ patients were in the case and control groups, respectively. A total of 14 patients $(14 / 39 ; 35.9 \%)$ were heterozygous $(\mathrm{C} / \mathrm{T}) ; 4$ $(4 / 20 ; 20 \%)$ patients were in the case and $10(10 / 19 ; 52.6 \%)$ patients were in the control groups. Six patients $(6 / 39 ; 15.3 \%)$ were wild-type $(\mathrm{C} / \mathrm{C}) ; 5(25 / 20 ; 25 \%)$ patients were in the case group $(1 / 19 ; 5.2 \%)$ and 1 patient was in the control group. No patients were homozygous for CYP $2 D^{* 4}$ $(1846 \mathrm{G}>\mathrm{A})$. We found the heterozygous CYP2D $6 * 4$ genotype in 1 patient $(2.56 \%)$. Allele frequency of CYP2D $6 * 4$ $(1846 \mathrm{G}>\mathrm{A})$ was $1.28 \%$. A total of 38 patients $(97.43 \%)$ carried the wild-type allele. The CYP2D6*5 (deletion) was not found in this population. Details of genotype and allele frequencies in each group are shown in Table 2.

\section{Clinical outcome by genotype}

Patients with CYP2D $6 * 10$ homozygous variant $(\mathrm{T} / \mathrm{T}$; $C Y P 2 D 6 * 10 / * 10$ ) had a significantly shorter DFS than those with the heterozygous variant (C/T; CYP $\left.2 D 6 \mathrm{Wt} /{ }^{*} 10\right)$ ( $P=0.036$, Figure 1A). Furthermore, there was a significant difference in DFS between homozygous wild-type $(\mathrm{C} / \mathrm{C}$; CYP2D6 Wt/Wt and heterozygous variant $(\mathrm{C} / \mathrm{T}$; CYP2D6 $\left.W t /{ }^{*} 10\right)(P=0.008$, Figure $1 C)$. In contrast to many previous studies, there was no significant difference in DFS between heterozygous variants, homozygous variants $(\mathrm{T} / \mathrm{T}$; $\left.C Y P 2 D 6^{*} 10 / * 10\right)$, and homozygous wild-type patients $(\mathrm{C} / \mathrm{C} ; C Y P 2 D 6 \mathrm{Wt} / W t)(P=0.316$, Figure 1B). Because we found the heterozygous CYP2D6*4 G/A $(1846 \mathrm{G}>\mathrm{A})$ only in one patient, we did not analyze this association. Notably, this patient also had CYP2D6*10/*10 (T/T) and was classified as an intermediate metabolizer. Her DFS was only 22.7 months.

\section{Discussion}

Many recent studies have demonstrated a correlation between CYP2D6 polymorphisms and the efficacy of tamoxifen treatment in ER-positive breast cancer. ${ }^{13,24,25}$ Most studies were in Caucasians, which found that CYP2D6*4 causes a poor metabolizer phenotype in

Table 2 Genotype and allele frequencies

\begin{tabular}{|c|c|c|c|}
\hline \multirow[t]{2}{*}{ Polymorphisms } & \multicolumn{2}{|c|}{ Allele frequencies } & \multirow[t]{2}{*}{$P$-value } \\
\hline & $\begin{array}{l}\text { Case } \\
(n=20)\end{array}$ & $\begin{array}{l}\text { Control } \\
(n=19)\end{array}$ & \\
\hline CYP2D6*10 & & & 0.058 \\
\hline \multicolumn{4}{|l|}{$(100 C>T)$} \\
\hline $\mathrm{T} / \mathrm{T}$ & II (55\%) & $8(42.1 \%)$ & \\
\hline $\mathrm{C} / \mathrm{T}$ & $4(20 \%)$ & $10(52.6 \%)$ & \\
\hline $\mathrm{C} / \mathrm{C}$ & $5(25 \%)$ & I (5.3\%) & \\
\hline CYP2D6*4 & & & 0.323 \\
\hline \multicolumn{4}{|l|}{$(I 846 G>A)$} \\
\hline $\mathrm{A} / \mathrm{A}$ & $0(0 \%)$ & $0(0 \%)$ & \\
\hline $\mathrm{G} / \mathrm{A}$ & I (5\%) & $0(0 \%)$ & \\
\hline G/G & $19(95 \%)$ & 19 (100\%) & \\
\hline
\end{tabular}


A

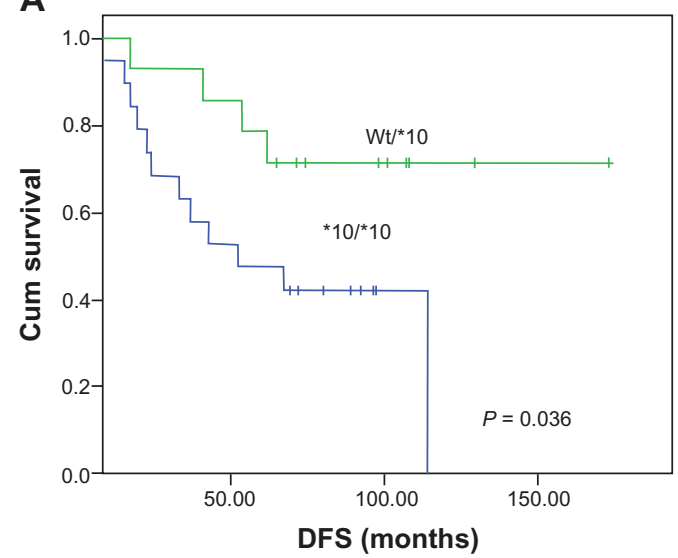

B

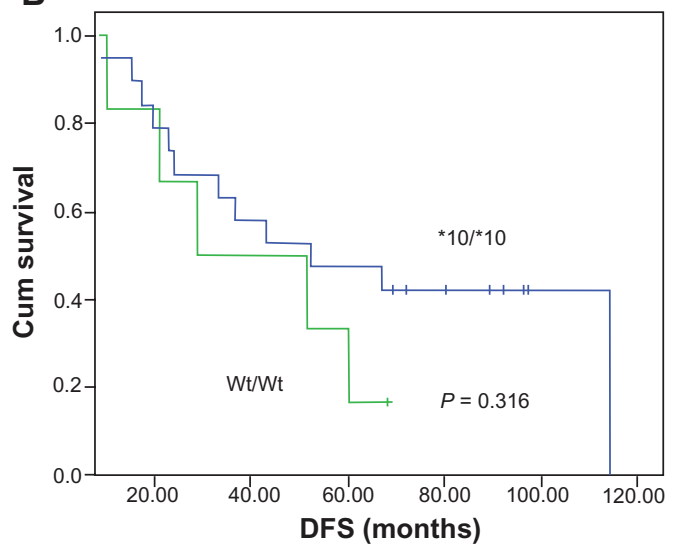

C

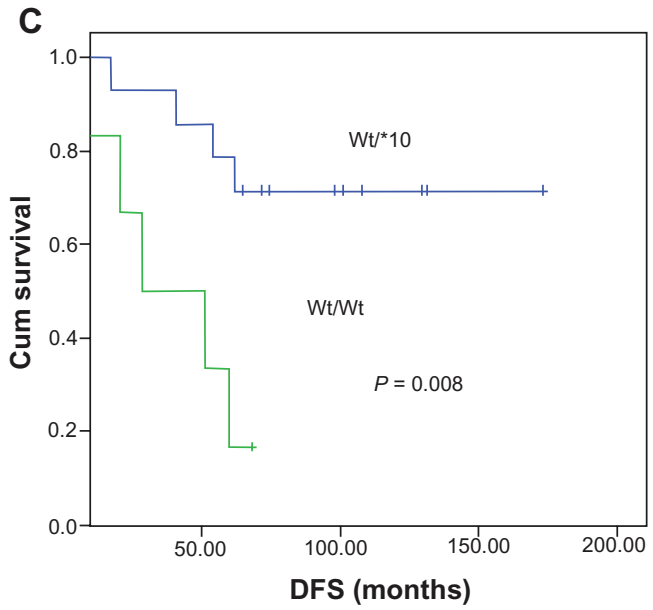

Figure I Kaplan-Meier estimates of disease-free survival (DFS) with the CYP2D6*10 genotype in 39 Thai breast cancer patients receiving tamoxifen treatment. Patients with the CYP2D6*10 homozygous variant $\mathrm{T} / \mathrm{T}$ genotype were compared with patients with heterozygous $\mathrm{C} / \mathrm{T}(\mathbf{A})$ or homozygous wild-type $\mathrm{C} / \mathrm{C}$ genotype $(\mathbf{B})$ and heterozygous $\mathrm{C} / \mathrm{T}$ compared with homozygous wild-type $\mathrm{C} / \mathrm{C}$ genotype (C).

$12 \%-20 \%$ of the Caucasian population. CYP $2 D 6 * 4$ was found in only $1 \%-2 \%$ of the Asian population, while CYP $2 D 6 * 10(100 \mathrm{C}>\mathrm{T})$ causes the intermediate metabolizer phenotype and is found in $40 \%-50 \%$ of the Asian population. ${ }^{11,26}$ Several studies have been performed primarily in Caucasian women. ${ }^{14-17}$ The relatively few studies in Asian women ${ }^{19,20}$ have suggested that CYP2D6 status is associated with outcomes in prevention, adjuvant, and metastatic settings. Recently, studies in Asian populations report a correlation between $C Y P 2 D 6^{*} 10$ and the impact on the clinical outcome of ER-positive breast cancer. ${ }^{19,20,22}$ However, whether $C Y P 2 D 6^{*} 10$ genotypes influence the clinical effect in Thai breast cancer patients is still unclear. ${ }^{21,22}$ This study was the first to explore this correlation in Thai patients. We designed this case-control study to investigate the relationship between $C Y P 2 D 6^{*} 10$ and clinical outcomes.

Our study found a high frequency of the CYP $2 D \sigma^{*} 10$ homozygous variant $\mathrm{T} / \mathrm{T}$ genotype in $48.71 \%$ of patients, which agrees with the frequency of $40 \%-50 \%$ found in previous studies. ${ }^{3}$ CYP2D6*4/*4 (G/G; 1846G > A) was not detected in our study, which agrees with previous reports that $C Y P 2 D 6 * 4 / * 4$ is rare in Asian populations $(1 \%-3 \%) .{ }^{19-22}$ The SNP of CYP $2 D 6^{*} 10(100 \mathrm{C}>\mathrm{T})$ that we found in our study had previously been reported as a common SNP in Asian populations. ${ }^{20-22}$ Our study found that patients with the T/T genotype had a significantly shorter DFS than those with the $\mathrm{C} / \mathrm{T}$ genotype, but DFS was not significantly different compared with the $\mathrm{C} / \mathrm{C}$ genotype. This is in contrast to previous reports. ${ }^{21}$

We then explored the baseline characteristics of all patients, including the addition of the chemotherapy regimen, which we thought might impact the outcome. We found that three of six CYP2D6 $(\mathrm{C} / \mathrm{C} ; 100 \mathrm{C}>\mathrm{T})$ patients had involvement of more than four lymph nodes and that this proportion was higher than for the other two genotypes, but not statistically significant. The regimen of chemotherapy was not a confounding factor in this study. This may be due to the small number of patients in the study. However, we matched one control subject per case patient to avoid clinical confounding factors in this analysis. Other limitations of this case-control study include our inability to control other confounding factors, such as compliance with tamoxifen treatment and the family history of breast cancer, which may influence clinical outcome. However, we still found a trend of lower DFS in patients with the CYP2D $6^{*} 10$ homozygous variant $\mathrm{T} / \mathrm{T}$ genotype when analyzed and compared with the other two genotypes, although statistical significance was not reached. We consider that this is acceptable in a pilot study such as this, but future research should include a larger patient sample population and be prospective in order to accurately identify the correlation between $C Y P 2 D 6^{*} 10$, and $C Y P 2 D 6 * 5$ polymorphisms and clinical outcome in Thai ER-positive breast cancer patients. 
In summary, our findings demonstrated a high frequency of the CYP2D6*10 homozygous variant T/T genotype, similarly to observations in other Asian populations. This genotype could lead to a reduced benefit of adjuvant tamoxifen and negatively affect the clinical outcome in Thai ERpositive breast cancer patients. In addition, it is reasonable to explore $C Y P 2 D 6 * 10$ rather than $C Y P 2 D 6 * 4$ due to the higher frequency of $C Y P 2 D 6^{*} 10$, even in a small patient sample, such as in this study.

\section{Disclosure}

The authors declare that they have no competing or conflicts of interest.

\section{References}

1. Hoskins JM, Carey LA, McLeod HL. CYP2D6 and tamoxifen: DNA matters in breast cancer. Nat Rev Cancer. 2009;9(8):576-586.

2. Desta Z, Ward BA, Soukhova NV, Flockhart DA. Comprehensive evaluation of tamoxifen sequential biotransformation by the human cytochrome P450 system in vitro: prominent roles for CYP3A and CYP2D6. J Pharmacol Exp Ther. 2004;310(3):1062-1075.

3. Lim YC, Li L, Desta Z, et al. Endoxifen, a secondary metabolite of tamoxifen, and 4-OH-tamoxifen induce similar changes in global gene expression patterns in MCF-7 breast cancer cells. J Pharmacol Exp Ther. 2006;318(2):503-512.

4. Fabian C, Tilzer L, Sternson L. Comparative binding affinities of tamoxifen, 4-hydroxytamoxifen,and desmethyltamoxifen for estrogen receptor isolated from human breast carcinoma: correlation with blood levels in patients with metastatic breast cancer. Biopharma Drug Dispos. 1981;2(4):381-390.

5. Jin Y, Desta Z, Stearns V, et al. CYP2D6 genotype, antidepressant use, and tamoxifen metabolism during adjuvant breast cancer treatment. J Natl Cancer Inst. 2005;97(1):30-39.

6. Early Breast Cancer Trialists' Collaborative Group (EBCTCG). Effects of chemotherapy and hormonal therapy for early breast cancer on recurrence and 15-year survival: an overview of the randomised trials. Lancet. 2005;365(9472):1687-1717.

7. Higgins MJ, Stearns V. Understanding resistance to tamoxifen in hormone receptor-positive breast cancer. Clin Chem. 2009;55(8):1453-1455.

8. Goetz MP, Rae JM, Suman VJ, et al. Pharmacogenetics of tamoxifen biotransformation is associated with clinical outcomes of efficacy and hot flashes. J Clin Oncol. 2005;23(36):9312-9318.

9. Knox SK, Ingle JN, Suman VJ, et al. Cytochrome P450 2D6 status predicts breast cancer relapse in women receiving adjuvant tamoxifen (Tam). J Clin Oncol. 2006;24(18S);504.

10. Stearns V, Johnson MD, Rae JM, et al. Active tamoxifen metabolite plasma concentrations after coadministration of tamoxifen and the selective serotonin reuptake inhibitor paroxetine. J Natl Cancer Inst. 2003;95(23):1758-1564.
11. Lim H-S, Ju Lee H, Seok Lee K, Sook Lee E, Jang IJ, Ro J. Clinical implications of CYP2D6 genotypes predictive of tamoxifen pharmacokinetics in metastatic breast cancer. $J$ Clin Oncol. 2007;25(25):3837-3845.

12. Borges S, Desta Z, Li L, et al. Quantitative effect of CYP2D6 genotype and inhibitors on tamoxifen metabolism: implication for optimization of breast cancer treatment. Clin Pharmacol Ther. 2006;80(1):61-74.

13. Lim JSL, Chen XA, Singh O, et al. Impact of CYP2D6, CYP3A5, CYP2C9 and CYP2C19 polymorphisms on tamoxifen pharmacokinetics in Asian breast cancer patients. Br J Clin Pharmacol. 2011;71(5): 737-750.

14. Nowell S, Ahn J, Rae J, et al. Association of genetic variation in tamoxifen-metabolizing enzymes with overall survival and recurrence of disease in breast cancer patients. Breast Cancer Res Treat. 2005; 91(3):249-258.

15. Goetz MP, Schaid DJ, Wickerham DL, et al. Evaluation of CYP2D6 and efficacy of tamoxifen and raloxifene in women treated for breast cancer chemoprevention: results from the NSABP P1 and P2 clinical trials. Clin Cancer Res. 2011;17(21):6944-6951.

16. Schroth W, Antoniadou L, Fritz P, et al. Breast cancer treatment outcome with adjuvant tamoxifen relative to patient CYP2D6 and CYP2C19 genotypes. J Clin Oncol. 2007;25(33):5187-5193.

17. Schroth W, Goetz MP, Hamann U, et al. Association between CYP2D6 polymorphisms and outcomes among women with early stage breast cancer treated with tamoxifen. JAMA. 2009;302(13):1429-1436.

18. Schroth W, Hamann U, Fasching PA, et al. CYP2D6 polymorphisms as predictors of outcome in breast cancer patients treated with tamoxifen: expanded polymorphism coverage improves risk stratification. Clin Cancer Res. 2010;16(17):4468-4477.

19. Kiyotani K, Mushiroda T, Sasa M, et al. Impact of CYP2D6*10 on recurrence-free survival in breast cancer patients receiving adjuvant tamoxifen therapy. Cancer Sci. 2008;99(5):995-999.

20. Xu Y, Sun Y, Yao L, et al. Association between CYP2D6*10 genotype and survival of breast cancer patients receiving tamoxifen treatment. Ann Oncol. 2008;19(8):1423-1429.

21. Toyama T, Yamashita H, Sugiura H, Kondo N, Iwase H, Fujii Y. No association between CYP2D6*10 genotype and survival of nodenegative Japanese breast cancer patients receiving adjuvant tamoxifen treatment. Jpn J Clin Oncol. 2009;39(10):651-656.

22. Pechatanan K, Jaruhathai S, Ativitavas T, et al. Cytochrome P450 2D6 polymorphisms of Thai breast cancer patients and their outcomes of adjuvant tamoxifen. J Clin Oncol. 2007; Suppl:Abstr e11037.

23. Bonanni B, Macis D, Maisonneuve P, et al. Polymorphism in the CYP2D6 tamoxifen-metabolizing gene influences clinical effect but not hot flash: data from the Italian Tamoxifen Trial. J Clin Oncol. 2006;24(22):3708-3709.

24. The LK, Mohamed NI, Salleh MZ, et al. The risk of recurrence in breast cancer patients treated with tamoxifen: polymorphisms of CYP2D6 and ABCB1. AAPS J. 2012;14(1):52-59.

25. Fleeman N, Martin Saborido C, Payne K, et al. The clinical effectiveness and cost-effectiveness of genotyping for CYP2D6 for the management of women with breast cancer treated with tamoxifen: a systematic review. Health Technol Assess. 2011;15(33):1-102.

26. Ramamoorthy Y, Tyndale RF, Sellers EM. Cytochrome P450 2D6.1 and cytochrome P450 2D6.10 differ in catalytic activity for multiple substrates. Pharmacogenetics. 2001;11(6):477-487.
Pharmacogenomics and Personalized Medicine

\section{Publish your work in this journal}

Pharmacogenomics and Personalized Medicine is an international, peerreviewed, open access journal characterizing the influence of genotype on pharmacology leading to the development of personalized treatment programs and individualized drug selection for improved safety, efficacy and sustainability. This journal is indexed on the American Chemical

\section{Dovepress}

Society's Chemical Abstracts Service (CAS). The manuscript management system is completely online and includes a very quick and fair peer-review system, which is all easy to use. Visit http://www.dovepress. com/testimonials.php to read real quotes from published authors. 